\title{
Aplikasi Media Pembelajaran Kognitif Untuk Anak Usia 5 Sampai 6 Tahun pada Taman Kanak-Kanak Jati Kencana
}

\author{
Anton Respati Pamungkas*1, Kristono ${ }^{2}$, Rizky Dwi ${ }^{3}$ \\ 1,2,3Program Studi Sistem Informasi, STMIK AUB, Surakarta, Indonesia \\ e-mail: *1 anton18@stmik-aub.ac.id, ${ }^{2}$ kristono@stmik-aub.ac.id,, ${ }^{3}$ rizkydwi@gmail.com
}

\begin{abstract}
Abstrak
Taman Kanak-Kanak Jati Kencana merupakan Taman Kanak-Kanak yang terdiri dari dua kelas setiap kelas yaitu kelas nol kecil dan kelas nol besar. Anak usia kanak-kanak pada dasarnya memiliki perkembangan kognitif yang sangat baik. Untuk membantu anak didik pada Taman Kanak-Kanak Jati Kencana perlu dibuatkan sebuah aplikasi media pembelajaran kognitif untuk anak usia 5 sampai 6 tahun dengan tema lingkunganku, kebutuhanku, pekerjaan dan air, udara dan api. Pada aplikasi tersebut akan dibuatkan contoh soal-soal yang dikemas dalam bentuk game yang menarik. Metode yang digunakan dalam pengembangan sistem yaitu waterfall. Untuk metode kelemahan sistem menggunakan analisa PIECES, menggambarkan alur menggunakan Unified Modeling Languange, firebase Android Studio dan pengolahamn database menggunakan MySQL. Berdasarkan pengujian yang telah dilakukan dengan menggunakkan blackbox testing, aplikasi yang dibangun dapat membantu masalah yang dihadapi pada Taman Kanak-Kanak Jati Kencana.
\end{abstract}

Kata kunci: Taman Kanak-Kanak Jati Kencana, Aplikasi Media Pembelajaran, Android

\section{PENDAHULUAN}

Pendidikan mempunyai peranan penting dalam kehidupan berbangsa dan bernegara. Hal ini terdapat dalam Undang-undang RI Tahun No. 20 Tahun 2003 tentang sistem pendidikan nasional, Pendidikan adalah usaha dasar dan terencana untuk mewujudkan suasana belajar dan proses pembelajaran agar peserta didik secara aktif mengembangkan potensi dirinya memiliki spiritual keagaman, pengendalian diri, kepribadian, kecerdasan, akhlak mulia, serta ketrampilan yang diperlukan dirinya, masyarakat, Bangsa dan Negara.

Anak merupakan bagian dari bangsa ini, mempunyai tanggung jawab dalam mensukseskan pendidikan dengan cara yang sesuai dengan tingkat perkembangannya yaitu memaksimalkan semua aspek perkembangan dari aspek kognitif, bahasa, efektif psikomotor dan sosial. Pada usia taman kanak-kanak perkembangan kognitif mempunyai peranan yang penting. Karena berkaitan dengan otak. Bahwa sampai usia 4 tahun otak manusia berfungsi $50 \%$, sampai usia 8 tahun otak manusia berfungsi $80 \%$, jadi sejak usia 8 tahun kecerdasan manusia hanya bertambah $20 \%$. Dengan demikian perlu perhatian yang lebih pada usia taman kanak-kanak.

Anak usia kanak-kanak pada dasarnya memiliki perkembangan kognitif yang sangat baik. Salah satu perkembangan anak kanak-kanak ialah kemampuan kognitif yaitu kemampuan pengelompokkan benda-benda yang sejenis, mengelompokkan bentuk, mengelompokkan rasa, membedakan warna, membedakan bau, serta menyebut bilangan dan mengenal bilangan 1 sampai 10 dengan baik. (Hanifah, 2009)

Metode pembelajaran yang digunakan pada Taman Kanak-Kanak Jati Kencana adalah metode tatap muka langsung dan konvensional. Metode tersebut cenderung membosankan bagi anak-anak didik. Dari hal tersebut timbul permasalahan dimana metode yang dilakukan dan 
karakteristik anak yang berbeda-beda sehingga menuntut para guru yang begitu besar padahal keterbatasan waktu, sumber daya manusia dan target pembelajaran yang ingin dicapai, menjadi tidak memungkinkan karena guru harus memberikan perhatian lebih pada anak-anak yang membutuhkan perhatian lebih sedangkan pembahasan materi dan kegiatan pembelajaran lainnya harus tetap berjalan.

Perkembangan teknologi smartphone yang bermanfaat bagi penguna diberbagai kalangan. Saat ini muncul sebuah smartphone yang menggunakan OS (Operating Sistem) berbasis Android. Dimana Android menyediakan platform terbuka bagi para pengembang untuk menciptakan aplikasi mereka sendiri, sehingga pengguna dapat menambahkan berbagai aplikasi sesuai keinganan. Smartphone dapat bermanfaat di dalam berbagai bidang, seperti komunikasi, hiburan dan pendidikan. Di bidang pendidikan khususnya, smartphone dapat dimanfaatkan untuk membantu siswa dalam belajarnya dengan menambahkan aplikasi pendukung pelajaran.

Dari permasalahan tersebut penulis ingin merancang dan membangun sebuah Aplikasi Android, yang dapat menjadi media lain bagi guru agar tujuan dan target pembelajaran dapat tercapai dengan sukses. Selain itu, aplikasi yang dibangun dapat menjadi media pembelajaran mandiri diluar pendidikan formal (sekolah). Adanya media pembelajaran berupa aplikasi yang dikemas dengan kolaborasi teknologi multimedia diharapkan pembelajaran tidak lagi membosankan, sehingga anak-anak mempunyai semangat belajar yang tinggi.

Berdasarkan permasalahan yang ada di Taman Kanak-Kanak Jati Kencana, maka mendorong penulis untuk membuat sebuah aplikasi media pembelajaran kognitif untuk anak usia 5 sampai 6 tahun dengan tema lingkunganku, kebutuhanku, pekerjaan dan air, udara dan api. Tema yang diambil merupakan keadaan yang ada di lingkungan sekitar anak, sehingga anak akan lebih cepat memahami materi yang diajarkan. Pada aplikasi tersebut akan dibuatkan contoh soal-soal yang dikemas dalam bentuk kuis yang menarik. Selain pemahaman materi, anak-anak juga dapat langsung menerapkan materi tersebut dalam lingkungan sekitar mereka. Untuk selanjutnya dalam penyusunan Skripsi ini penulis menyajikan judul "Aplikasi Media Pembelajaran Kognitif Untuk Anak Usia 5 sampai 6 Tahun Pada Taman Kanak-Kanak Jati Kencana”.

\section{METODE PENELITIAN}

\subsection{Analisa Sistem}

Analisa sistem dilakukan dalam membangun sebuah aplikasi dengan tujuan untuk memahami permasalahan yang ada pada sistem, menganalisis sistem yang lama dapat mengetahui ruang lingkup yang ada yaitu pemilihan tema, pembuatan game dan penyampaian materi pembelajaran. Untuk menganalisa kelemahan sistem diperlukan langkah untuk mengidentifikasi dan memberikan solusi terhadap kelemahan sistem yang ada, maka sebagai landasan penulis menggunakan metode atau kerangka PIECES yang terdiri dari performance, information, economy, control, efficiency dan service. Analisis ini digunakan sebagai alat ukur untuk menentukan sistem baru layak atau tidak karena enam aspek ini harus mengalami peningkatan ukuran yang lebih baik dari sistem lama agar dapat mendukung dalam kelancaran proses perancangan.

Tabel 1. Tabel Analisis Kelemahan Sistem

\begin{tabular}{|l|l|}
\hline \multicolumn{1}{|c|}{ Analisa } & \multicolumn{3}{|c|}{ Yang sedang berjalan } \\
\hline $\begin{array}{l}\text { Perfomance } \\
\text { (Kinerja) }\end{array}$ & $\begin{array}{l}\text { Kegiatan pembelajaran dilakukan secara manual, dimana guru } \\
\text { menerangkan dan anak didik mendengarkan penjelasan dari guru. }\end{array}$ \\
\hline $\begin{array}{l}\text { Information } \\
\text { (Informasi) }\end{array}$ & $\begin{array}{l}\text { Informasi mengenai pembelajaran belum sepenuhnya dapat diterima } \\
\text { oleh anak didik, mengingat usia yang masih kanak-kanak dan kadang } \\
\text { merasa bosan dengan materi yang disampaikan oleh guru. }\end{array}$ \\
\hline $\begin{array}{l}\text { Economy } \\
\text { (Ekonomi) }\end{array}$ & $\begin{array}{l}\text { Biaya yang dikeluarkan relative tinggi, karena setiap tema } \\
\text { menggunakan buku atau lembar kerja siswa yang berbeda, disamping } \\
\text { murid yang harus membeli, guru juga harus membeli buku tersebut }\end{array}$ \\
\hline
\end{tabular}

GO INFOTECH: JURNAL ILMIAH STMIK AUB Vol. 25, No. 1, Juni 2019 : 1 - 10 


\begin{tabular}{|l|l|}
\hline & sebagai panduan mengajar. \\
\hline $\begin{array}{l}\text { Control } \\
\text { (Keamanan) }\end{array}$ & $\begin{array}{l}\text { Keamanan data sangat kurang, karena media pengajaran menggunakan } \\
\text { kertas tentu saja rawan hilang atau rusak karena air maupun bahan } \\
\text { lainnya yang mampu merusak kertas. }\end{array}$ \\
\hline $\begin{array}{l}\text { Efficiency } \\
\text { (Efisiensi) }\end{array}$ & $\begin{array}{l}\text { Dalam media pembelajaran guru harus mencari materi, mencari buku } \\
\text { anak didik, mengonateksi pekerjaan anak didik serta memberikan nilai } \\
\text { pada pekerjaan anak didik. }\end{array}$ \\
\hline $\begin{array}{l}\text { Service } \\
\text { (Layanan) }\end{array}$ & $\begin{array}{l}\text { Pelayanan yang diberikan oleh guru sudah baik, namun banyaknya anak } \\
\text { didik yang diajar sehingga belum mampu menjangkau pengetahuan } \\
\text { seluruh anak didik. }\end{array}$ \\
\hline
\end{tabular}

\subsection{Perancangan Sistem}

Perancangan sistem adalah merancang atau mendesain suatu sistem yang baik, yang isinya adalah langkah-langkah operasi dalam proses pengolahan data dan prosedur untuk mendukung operasi sistem. Perancangan sistem juga mencakup evaluasi efektivitas dab efisiensi relatif atas pilihan-pilihan rancang bangun sistem yang dipandang dari kebutuhan keseluruhan. Perancangan sistem atau proses menspesifikasikan rincian solusi yang dipilih oleh proses analisis sistem.

Tabel 2. Flowchart Sistem Yang Dibangun

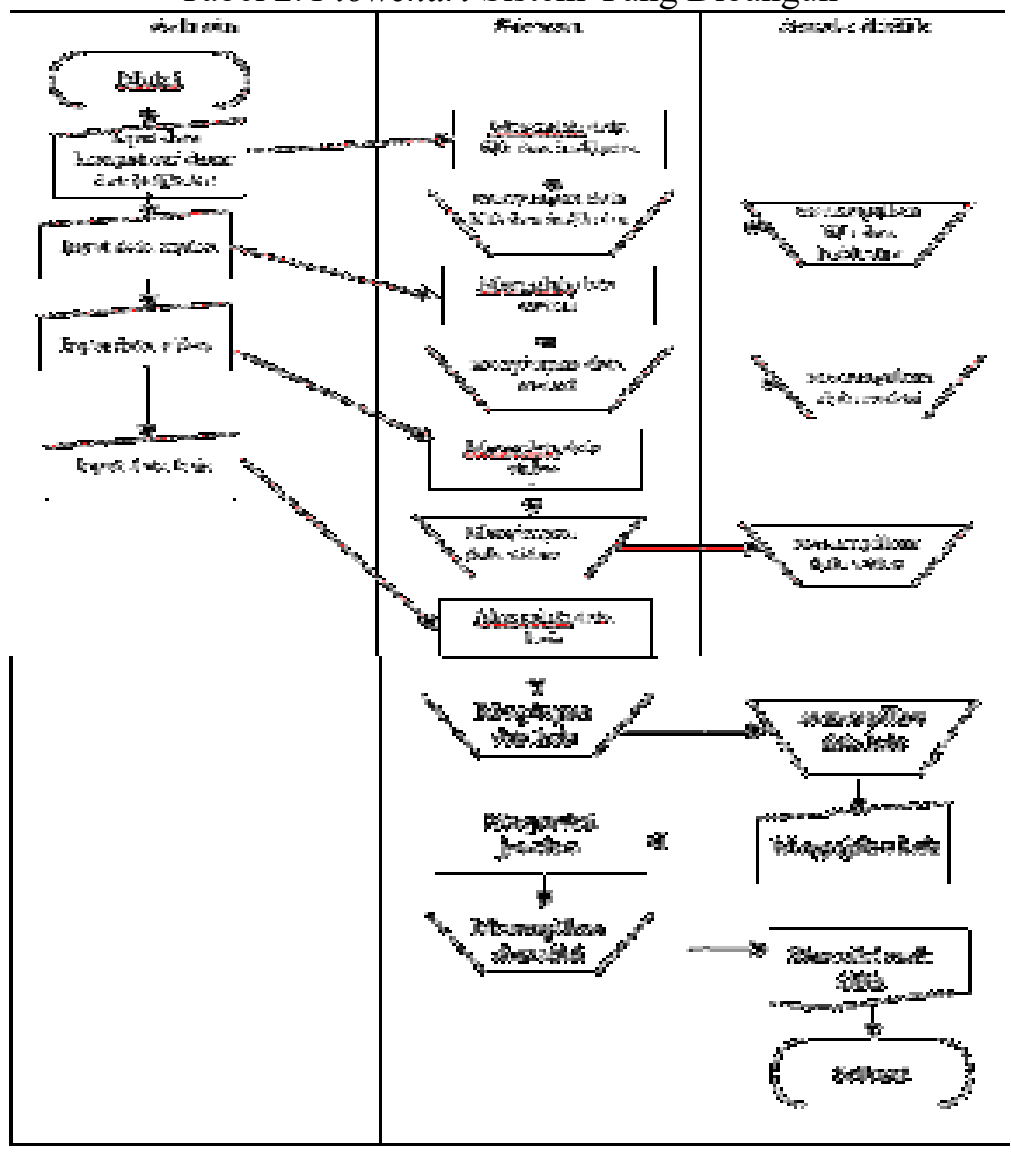

\section{HASIL DAN PEMBAHASAN}

Dalam pembuatan aplikasi ini dibutuhkan suatu pembahasan untuk menguraikan program dan analisis dari hasil program yang telah dibuat. Tujuan pembahasan ini adalah untuk mengetahui apakah program yang dibuat sudah bekerja seperti yang diharapkan atau belum. Berikut adalah proses pembahasan interface atau antarmuka program: 
3.1. Antar muka admin

1. Halaman Login Admin

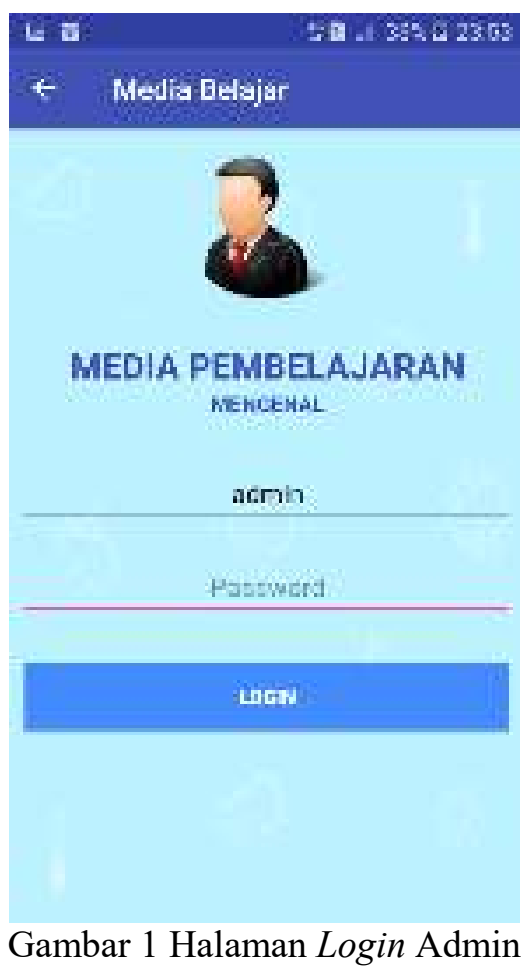

Keterangan gambar 1 Halaman Login Admin merupakan halaman yang digunakan oleh admin untuk masuk kedalam aplikasi dan mengelola aplikasi media pembelajaran.

2. Halaman Menu Utama

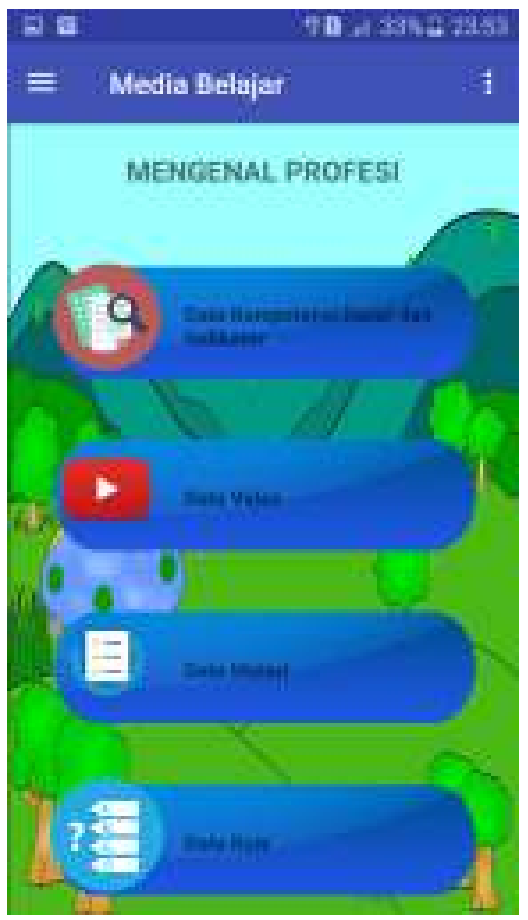

Gambar 2 Halaman Menu Utama

3. Halaman Kompetensi Dasar

GO INFOTECH: JURNAL ILMIAH STMIK AUB Vol. 25, No. 1, Juni 2019 : 1 - 10 
4. Halaman Indikator

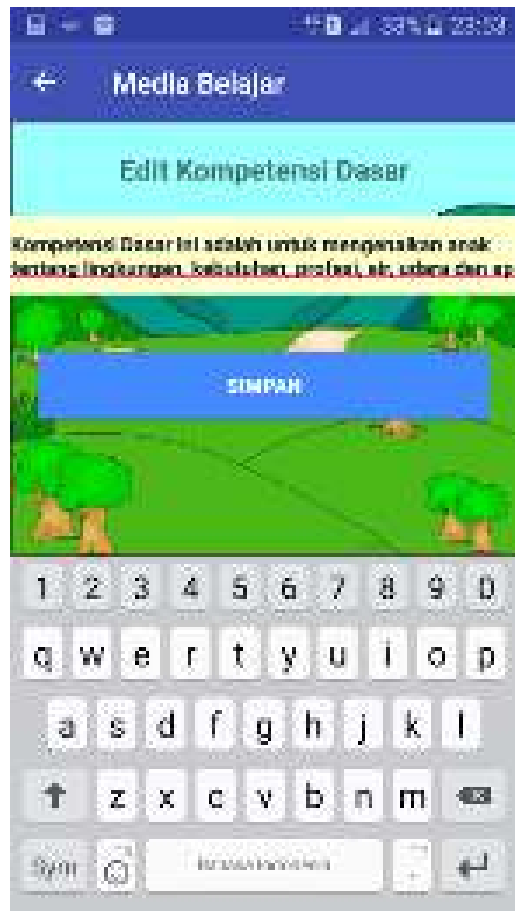

Gambar 3 Halaman Kompetensi Dasar

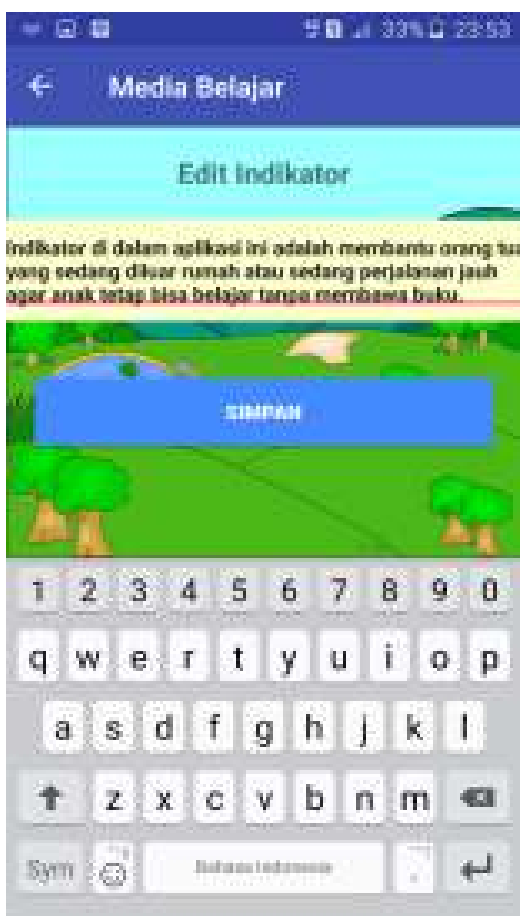

5. Halaman Data Materi

Gambar 4 Halaman Indikator 


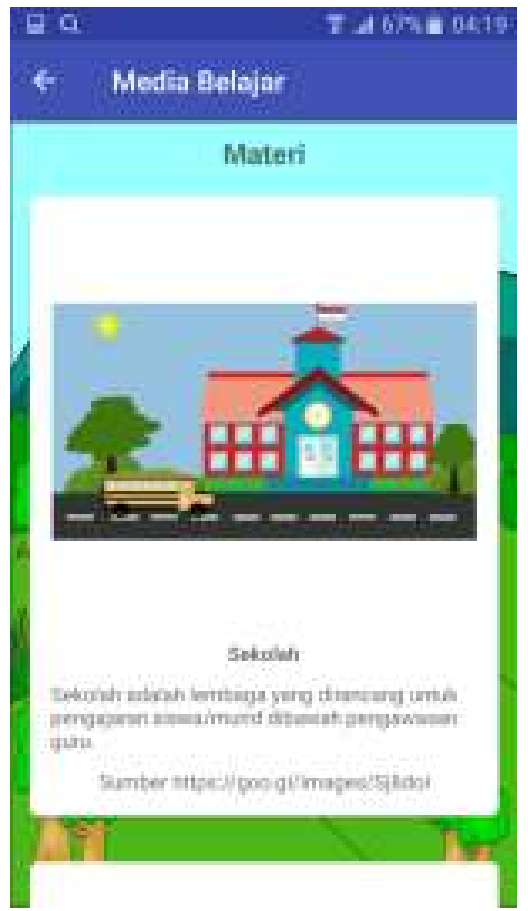

Gambar 5 Halaman Data Materi

Keterangan gambar 5 Halaman data materi, menampilkan materi-materi belajar sesuai dengan tema yang dipilih seperti pada gambar diatas.

6. Halaman Menu Video

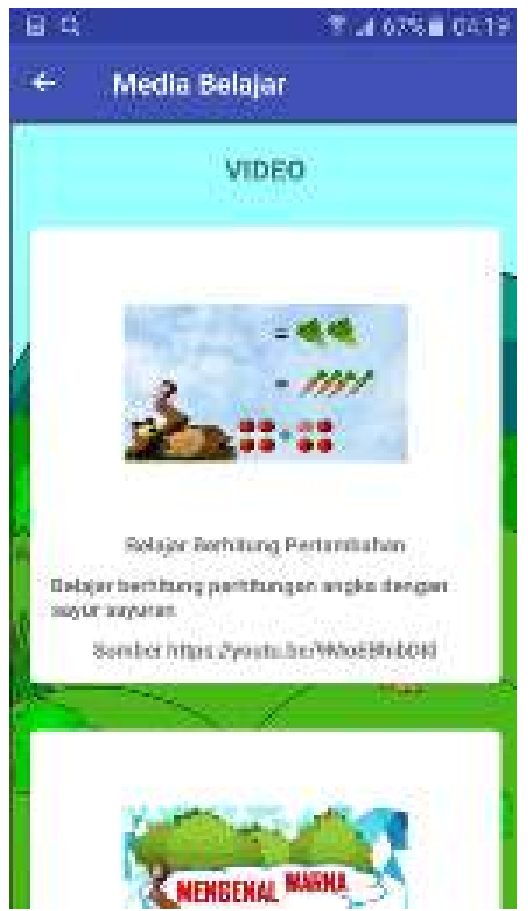

Gambar 6 Halaman Menu Video

Keterangan gambar 6 Halaman menu video menampilkan video interaktif pembelajaran, untuk menjalankan video klik pada gambar video tersebut.

7. Halaman Menu Kuis 


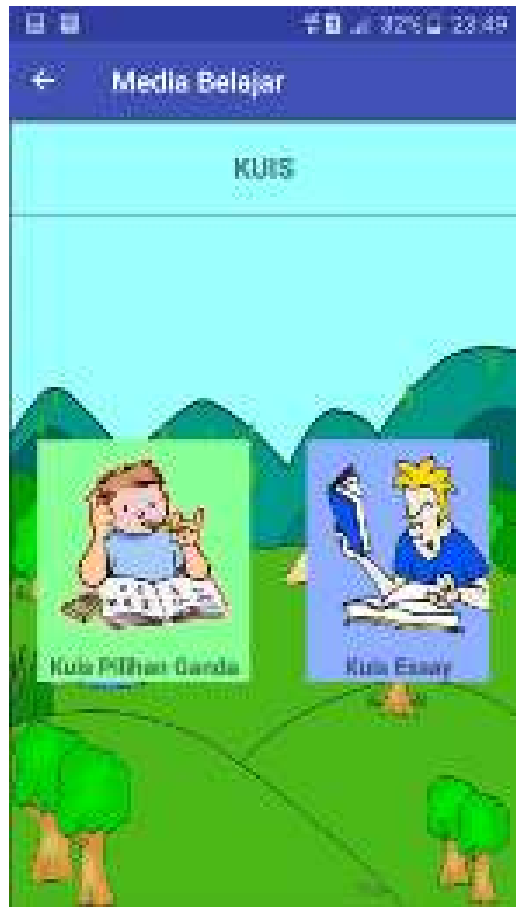

Gambar 7 Halaman Menu Kuis

Halaman menu kuis terdapat dua pilihan contoh metode soal. Yaitu kuis pilihan ganda dan kuis essay. Ketika siswa memilih salah satu menu kuis tersebut, sistem akan menampilkan daftar pertanyaaan-pertanyaan dan ketika selesai akan memperolah skor nilai.

8. Halaman Pertanyaan Pilihan Ganda

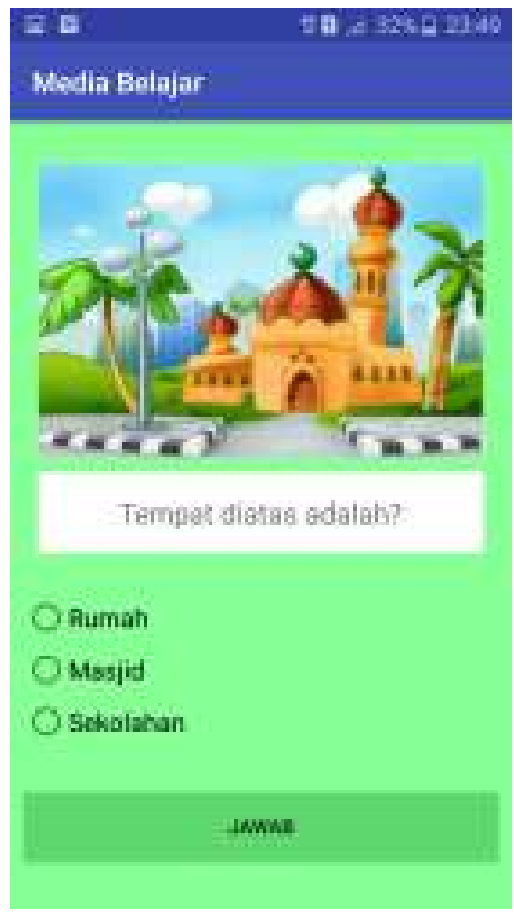

Gambar 8 Halaman Pertanyaan Pilihan Ganda

Keterangan gambar 8 Halaman pertanyaan pilihan ganda, menampilkan pertanyaan dengan pilihan jawaban pilihan ganda. Terdiri dari 1 soal gambar kemudian dibawahnya terdapat pilhan jawaban. Untuk menjawab tinggal pilih 1 jawaban yang dianggap benar.

9. Halaman Pertanyaan Pilihan Essay 


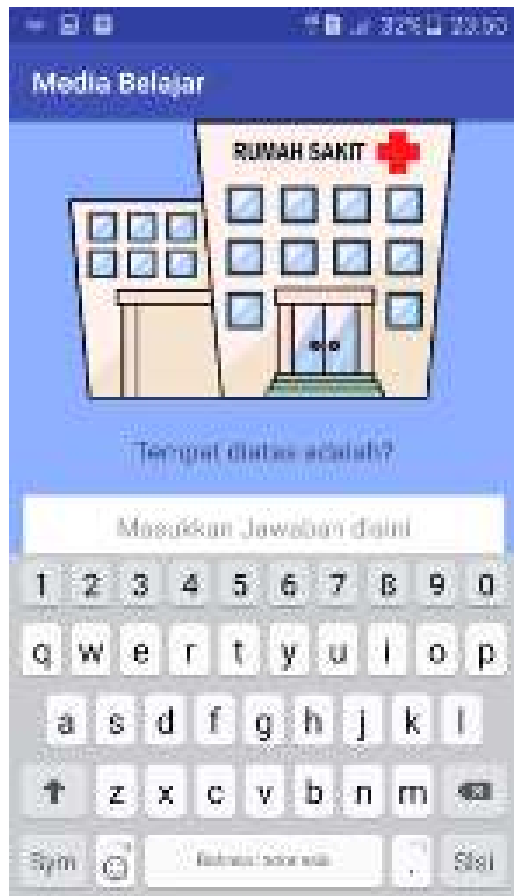

Gambar 9 Halaman Pertanyaan Pilihan Essay

Keterangan gambar 9 Halaman pertanyaan pilihan essay, merupakan kuis dengan sistem essay. Pada aplikasi menampilkan soal kemudian disediakan form untuk menuliskan jawaban dari pertanyaan tersebut.

10.Halaman Skor Nilai

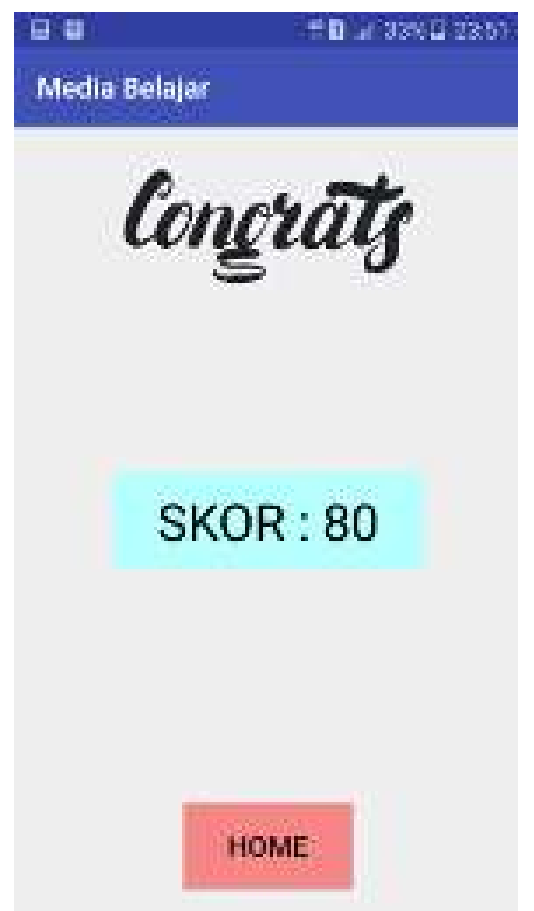

Gambar 10 Halaman Skor Nilai

Keterangan gambar 10 Halaman skor nilai menampilkan skor nilai dari anak didik yang sudah selesai menyelesaikan mengerjakan kuis. Untuk kembali ke halaman utama tekan tombol "home"

3.2. Antar muka web admin

1. Halaman Data Soal Pilihan Ganda 


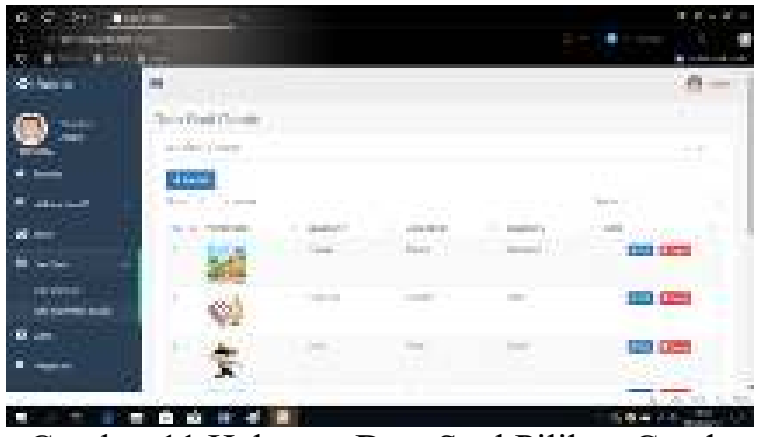

Gambar 11 Halaman Data Soal Pilihan Ganda

Keterangan gambar 11 Halaman data soal pilihan ganda menampilkan halaman data soal pilihan ganda yang dimiliki Taman Kanak-Kanak, informasi yang ditampilkan yaitu pertanyaan, jawaban, jawaban A, jawaban B, jawaban $C$, gambar. Untuk menambah data materi +Tambah pada atas table, hapus dan edit pada kolom tabel.

2. Halaman Data Video

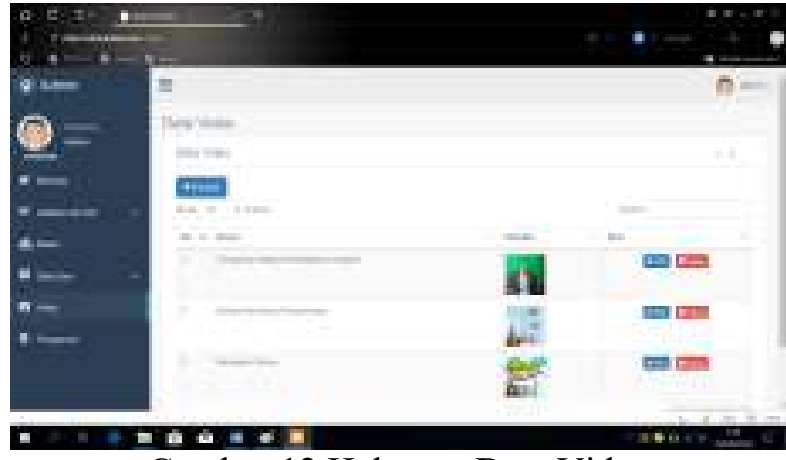

Gambar 12 Halaman Data Video

Keterangan gambar 12 Halaman data video menampilkan halaman data soal video yang dimiliki Taman Kanak-Kanak, informasi yang ditampilkan yaitu nama judul dan gambar. Untuk menambah data materi +Tambah pada atas table, hapus dan edit pada kolom tabel. s

3. Halaman Tambah Data Video

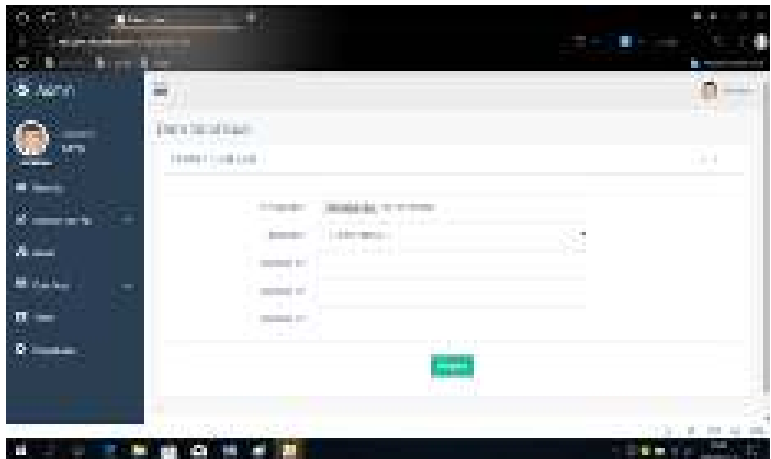

Gambar 13 Halaman Tambah Data Soal Pilihan Ganda

\section{KESIMPULAN}

Hasil perancangan Aplikasi Media Pembelajaran Kognitif Untuk Anak Usia 5 sampai 6 Tahun Pada Taman Kanak-Kanak Jati Kencana menggunakan metode pengembangan sistem waterfall. Untuk perancangan proses terdiri dari flowchart sistem, usecase diagram, activity, sequence diagram diagram dan relasi antar tabel. Perancangan Aplikasi Media Pembelajaran Kognitif Pada Anak Usia 5 sampai 6 Tahun pada Taman Kanak-Kanak Jati Kencana menggunakan Firebase Android Studio dan MySQL untuk pengolahan database. Aplikasi Media Pembelajaran Kognitif Untuk Anak Usia 5 sampai 6 Tahun Pada Taman Kanak-Kanak Jati Kencana dilengkapi dengan halaman admin, sehingga admin dapat mengelola aplikasi 
media pembelajaran sendiri, seperti untuk menambah materi, menambah video, menambah latihan soal kuis. Aplikasi Media Pembelajaran Kognitif Pada Anak Usia 5 sampai 6 Tahun pada Taman Kanak-Kanak Jati Kencana, digunakan sebagai media pembelajaran anak didik Usia 5 sampai 6 Tahun yang lengkap berisi kompetensi dasar dan indikator pembelajaran, materi pembelajaran, video interaktif, kuis yang terdiri dari kuis pilihan ganda dan kuis essay. Aplikasi Media Pembelajaran Kognitif Untuk Anak Usia 5 sampai 6 Tahun Pada Taman KanakKanak Jati Kencana, telah di implementasikan pada instansi dijadikan bahan referensi pembelajaran yang baru.

\section{SARAN}

Aplikasi Media Pembelajaran Kognitif Untuk Anak Usia 5 sampai 6 Tahun Pada Taman Kanak-Kanak Jati Kencana, masih dapat dikembangkan lebih lanjut, yaitu : Menambahkan laporan grafik setiap bulan, supaya perkembangan anak didik bisa dapat dipantau setiap bulannya. Pada saat menambah data video, gambar thumbnail dibuat otomatis dari link youtube. Supaya tidak input gambar thumbnail secara manual. Aplikasi media pembelajaran dibuat untuk versi iOs, sehingga jangkauan ekosistem aplikasi bisa diperluas.

\section{DAFTAR PUSTAKA}

[1] Undang Undang Dasar Republik Indonesia No. 20 Tahun 2003 tentang Sistem Pendidikan Nasional.

[2] Hanifah Nanang \& Cucu Suhana. 2009. Konsep Strategi Pembelajaran. Bandung : PT Rafika Aditama.

[3] Andiansyah, Deni. 2015. Aplikasi Pendukung Perkembangan Kognitif Anak Usia 3-5 Tahun Berbasis Android (Pengenalan Huruf, Angka, Warna dan Bentuk). Skripsi

[4] Haryo, Y Sulistyanto Sunarto. 2015. Aplikasi Media pembelajaran Tematik Untuk Anak TK Berbasis Android. Skripsi

[5] Mukhasanah, Fitria. 2015. Aplikasi pengenalan Matematika Dasar Untuk Anak Usia Dini Berbasis Android. Skripsi

[6] Wikipedia. 2017. Aplikasi. https://id.wikipedia.org/wiki/Aplikasi diakses pada 26 Mei 2018.

[7] Asyar, Rayandra. 2011. Kreatif Mengembangkan Pembelajaran. Jakrata: GP Press.

[8] Safaat, Nazruddin. 2012. Android Pemrograman Aplikasi Mobile Smartphone dan Tablet PC Berbasis Android. Bandung : Informatika Bandung.

[9] Jeffrey L. Whitten, Lonnie D. Bentley, Kevin C. 2001. System Analysis and Design Methods 5thEd. McGraw-Hill.

[10] Sekaran, Uma. 2011. Metode Penelitian untuk Bisnis. Jakarta : Selemba Empat.

[11] Rahayu, Minto. 2007. Bahasa Indonesia Di Perguruan Tinggi. Jakarta : Grafindo

[12] Usman, Husnaini dan Akbar, Purnomo Setyadi. 2000. Metodologi Penelitian Sosial. Jakarta : PT. Bumi Aksara

[13] Jogiyanto, H.M. 2005. Analisa dan Desain Sistem Informasi: Pendekatan Terstruktur Teori dan Praktik Aplikasi Bisnis. ANDI, Jakarta.

[14] Suyanto, M. 2004. Analisa Dan Desain Aplikasi Multimedia Untuk Pemasaran. Yogyakarta : Andi.

[15] Shalahuddin, $M$ dan Rosa. 2015. Rekayasa Perangkat Lunak Tersruktur dan Berorientasi Objek. Bandung : Informatika.

[16] Andi, Kristanto. 2003. Perancangan Sistem Informasi. Gava Media, Yogyakarta.

[17] DeCoster. 2012. Pengertian Java Development Kit. http://library.binus.ac.id diaskes pada 28 Mei 2018.

[18] Sandi, Mulyana. 2014. Bikin Website dengan Aplikasi-aplikasi Gratis, Cepat, Mudah dan Murah. Yogyakarta : Mediakom. 